\title{
CÁLCULO DIFERENCIAL E INTEGRAL: UMA (RE)CONSTRUÇÃO DE SIGNIFICADOS UTILIZANDO TECNOLOGIA
}

\author{
Laílla Fernandes Lacerda ${ }^{2}$, Pedro Augusto Muylaert Reis Pessanha ${ }^{2}$, Sabrina de Fátima da \\ Silva Costa ${ }^{2}$, Márcia Valéria Azevedo de Almeida Ribeiro ${ }^{1}$
}

\begin{abstract}
RESUMO
LACERDA, L.F.; PESSANHA, P.A.M.R.; COSTA, S.F.S.; RIBEIRO, M.V.A.A. Cálculo diferencial e integral: uma (re)construção de significados utilizando tecnologia. Perspectivas Online: Exatas \& Engenharia, v.08, n.23 , p. 41 - 47, 2018.

Entre as disciplinas consideradas difíceis, os estudantes de engenharias, de modo geral, destacam o Cálculo. Dessa forma o ensino de Cálculo vem sendo motivo de muita preocupação entre pesquisadores, devido às dificuldades que os alunos apresentam no decorrer do curso superior. A experiência de professores mostra que os índices de reprovação nessa disciplina constituem um problema que exige um olhar especial. Esta situação leva a uma reflexão e impulsiona os professores a criar estratégias que possibilitem minimizar as

estudo de Cálculo. A preocupação com os altos índices de reprovação na disciplina de Cálculo Diferencial e Integral nos períodos iniciais dos cursos de Engenharia nos motiva a desenvolver este projeto que propõe o estudo de funções em ambiente informatizado com o objetivo de melhorar o desempenho dos alunos na disciplina de Cálculo. Este projeto será desenvolvido a partir da aplicação de atividades investigativas, para os alunos de Engenharia, no Laboratório de Informática, com o auxílio do software Winplot.
\end{abstract} dificuldades que os alunos apresentam no

Palavras-chave: Ensino de Cálculo; Estudo de funções; Ambiente Informatizado. 


\begin{abstract}
Among the disciplines considered difficult, students of engineering, in general, highlight the Calculus. In this way the teaching of Calculus has been cause for much concern among researchers, due to the difficulties that the students present during the course of higher education. The teacher's experience shows that the failure rates in this discipline are a problem that requires a special look. This situation leads us to a reflection and encourages teachers to create strategies that make it possible to minimize the difficulties students present

the high failure rates in the discipline of Differential and Integral Calculus in the initial periods of the Engineering courses motivates us to develop this project that proposes the study of functions in computerized environment with the objective of improving the students performance in the discipline of Calculus . This project will be developed from the application of investigative activities, for Engineering students, in the Computer Laboratory, with the help of the software Winplot.
\end{abstract} in the study of Calculus. The concern with

Keywords: Calculus Teaching; Study of functions; Computerized Environment.

\footnotetext{
${ }^{1}$ Mestre em Engenharia de Produção/Professora do ISECENSA - Institutos Superiores de Ensino do CENSA - ISECENSA Engenharia de Produção - Rua Salvador Correa, 139, Centro, Campos dos Goytacazes, RJ, CEP: 28035-310, Brasil

${ }^{2}$ Alunos de Iniciação Científica PROVIC/ISECENSA

(*) e-mail: mvaleria@censanet.com.br

Data de recebimento: 10/07/18 . Aceito para publicação: 20/12/18.
} 


\section{INTRODUÇÃO}

A sociedade vem passando por transformações ocasionadas pelo desenvolvimento tecnológico, na qual a escola não mais se justifica pela apresentação dos conteúdos de forma dissociada do uso das novas tecnologias. Neste novo cenário, cabe ao professor a busca de novos caminhos aliados à tecnologia para promover, efetivamente, o ensino e a aprendizagem.

Segundo Ponte (2003), as Tecnologias de Informação e Comunicação podem auxiliar o professor, criando situações diversificadas de aprendizagem. Tajra (2008) destaca que o uso do computador facilita o aprendizado de disciplinas consideradas difíceis.

Entre as disciplinas consideradas difíceis, os alunos universitários das engenharias, de modo geral, destacam o Cálculo. Dessa forma, o ensino de Cálculo vem sendo motivo de muita preocupação entre pesquisadores, devido às dificuldades que os alunos apresentam no decorrer do curso superior. Muitas pesquisas, provenientes dessa preocupação, podem ser encontradas em artigos, publicados em anais do ENEM (Encontro Nacional de Educação Matemática) e do COBENGE (Congresso Brasileiro de Ensino de Engenharia).

A experiência dos professores mostra que os índices de reprovação nessa disciplina constituem um problema que exige um olhar especial.

Segundo Meyer e Júnior (2002), o ensino de Cálculo, no Brasil, tem sido responsabilizado por um número muito grande de reprovações e evasões de universitários.

Silva, et al. (2002) destacam que o insucesso na disciplina de Cálculo decorre da falta de conhecimento por parte dos alunos, de alguns conceitos fundamentais, dentre eles o de função.

Sendo assim, este trabalho propõe o estudo de funções em ambiente informatizado com o objetivo de melhorar o desempenho dos alunos na disciplina de Cálculo.

Segundo Viana (2016), o conteúdo função permeia os principais tópicos abordados no Cálculo, tais como continuidade, diferenciação, integração e o Teorema fundamental do Cálculo.

A informática na educação apresentará grandes contribuições, desenvolvendo nos alunos a capacidade de pensar e tomar decisões, estimulando a criatividade e descoberta, tornando-se assim, um agente motivador e dinâmico no processo de ensino e aprendizagem (TAJRA, 2008). Ele ainda destaca que o professor terá o papel de facilitador do ensino e parceiro dos alunos, atendendo às suas necessidades individuais.

A motivação para desenvolver este projeto reside na preocupação com os altos índices de reprovação na disciplina de Cálculo Diferencial e Integral, principalmente, nos períodos iniciais dos cursos de Engenharia.

Esta situação leva os professores a uma reflexão e os impulsiona a pensar em estratégias que possibilitem minimizar as dificuldades que os alunos apresentam no estudo de Cálculo.

Diante dessa situação, deseja-se responder à seguinte questão: $\mathrm{O}$ estudo de funções em ambiente informatizado contribuirá para que os alunos tenham um desempenho melhor nas disciplinas de Cálculo?

Constitui-se como objetivo geral deste projeto criar um ambiente de aprendizagem investigativo, em que os alunos possam desenvolver o pensamento crítico, estimular a motivação para o estudo de Cálculo, construir e reconstruir conceitos, tendo a tecnologia como aliada para viabilizar as ações.

Persp. Online: exatas \& eng., Campos dos Goytacazes, 23 (08) 41 - 47 - 2018

seer.perspectivasonline.com.br 
Os objetivos específicos foram delineados da seguinte forma: (i) Despertar o interesse dos alunos pelo estudo de Cálculo a partir do uso da tecnologia; (ii) Utilizar a tecnologia para minimizar dificuldades que os alunos apresentam no estudo de Cálculo; (iii) Estudar funções com o auxílio do software Winplot.

Dessa forma, existem ferramentas que poderiam ser testadas para avaliar esse desempenho. Uma delas, é o Winplot, que é um software gráfico gratuito e de fácil manuseio, desenvolvido pelo professor Richard Parris, da Phillips Exeter Academy.

Segundo Corrêa (2015), a exploração de funções por meio de softwares pode enriquecer a aprendizagem dos alunos, na medida em que esses permitem a observação de características fundamentais no estudo qualitativo do comportamento de funções.

Giraldo (2013) ainda ressalta que as tecnologias computacionais permitem representar gráficos cartesianos de funções de forma dinâmica, acrescentando um novo ingrediente à abordagem tradicional.

\section{METODOLOGIA}

Este projeto foi desenvolvido a partir da elaboração e aplicação de atividades investigativas, de modo que os sujeitos envolvidos na pesquisa pudessem questionar e refletir sobre situações de aprendizagem que promovessem o ensino e a aprendizagem da disciplina de Cálculo.

À coordenadora do projeto, juntamente com os alunos voluntários, coube o papel de planejar e desenvolver situações de aprendizagem que permitissem auxiliar o ensino e a aprendizagem da disciplina de Cálculo.

As atividades foram aplicadas em encontros semanais no Laboratório de Informática do ISECENSA com o auxílio do software Winplot e com a presença do professor coordenador que teve o papel de orientar as ações e promover um trabalho integrado e participativo.

O Winplot é um software gratuito, de fácil manuseio, possui vários recursos para traçar e animar gráficos em 2D e 3D e está sempre atualizado na rede. Foi produzido por Richard Parris da Phillips Exeter Academy (http://math.exeter.edu/rparris).

Segundo Jesus (2001), alunos e professores do ensino superior, poderão desenvolver várias atividades com o Winplot, pela sua facilidade de manuseio e diversidade de recursos didáticos.

Ao término das atividades, foi aplicado um questionário de sondagem, com perguntas abertas e fechadas, com o objetivo de obter dados relevantes para a pesquisa, como perfil dos alunos participantes, uso de tecnologia em estudos anteriores, dificuldades apresentadas, comentários e sugestões.

\section{DESENVOLVIMENTO}

Inicialmente, os três alunos voluntários e a professora coordenadora, se reuniram para o estudo do tema, revisão bibliográfica e reconhecimento do software. Em seguida, prepararam atividades em que foram explorados conteúdos referentes às funções Afim, Quadrática, Exponencial e Logarítmica, tendo a tecnologia como aliada para facilitar a visualização e a construção de conceitos.

Persp. Online: exatas \& eng., Campos dos Goytacazes, 23 (08) 41 - 47 - 2018

seer.perspectivasonline.com.br 
As atividades foram aplicadas para doze alunos do ISECENSA, entre eles, nove alunos das Engenharias e três alunos de Arquitetura e Urbanismo, em encontros semanais, no Laboratório de Informática. A maioria dos alunos (67\%) cursava o primeiro período.

Foram elaboradas 11 atividades e estas eram desenvolvidas com o auxílio do software Winplot. Durante a aplicação das atividades os alunos aprendiam os comandos no Winplot e à medida que realizavam as atividades incorporavam novos conceitos aos já aprendidos em atividades anteriores.

As atividades referentes à Função Afim (Figura 1) tinham como objetivo identificar geometricamente o zero da Função Afim, bem como os seus coeficientes.

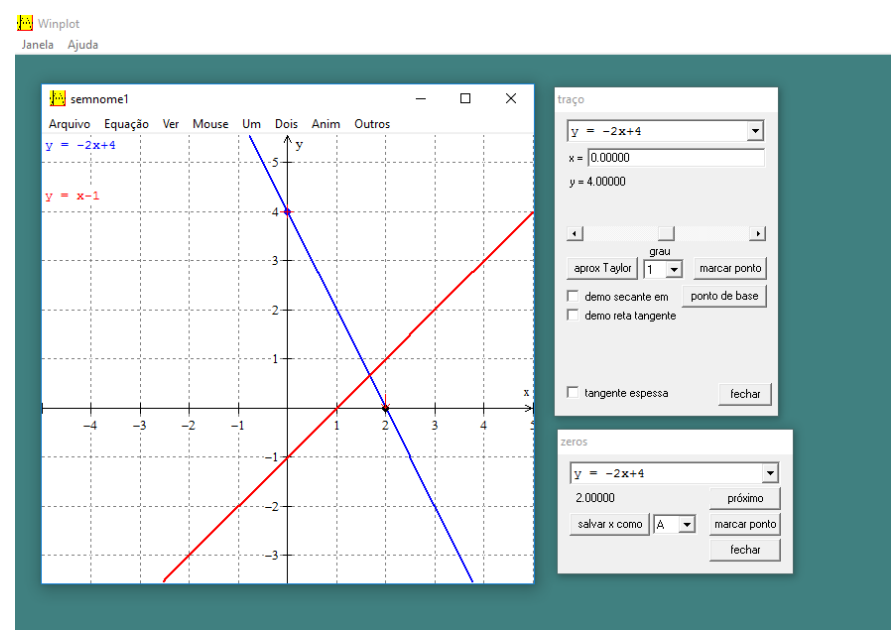

Figura 1: Função Afim

No caso das atividades da Função Quadrática (Figura 2), foram explorados graficamente os zeros da função e as coordenadas do vértice. Também foi possível analisar as translações verticais e horizontais do gráfico da Função Quadrática e estudar a forma canônica dessa função.

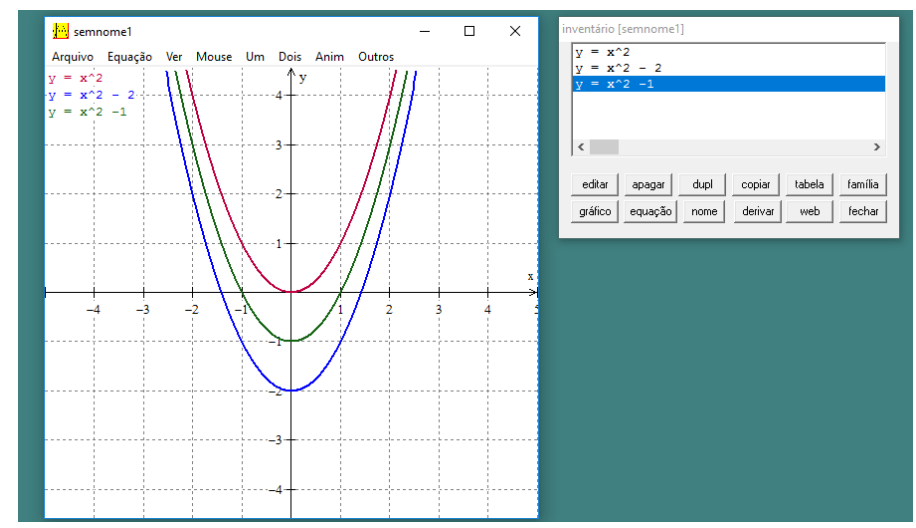

Figura 2: Função Quadrática

No que diz respeito às Funções Exponencial e Logarítmica (figura 3), os alunos puderam observar características gráficas pertinentes a estas funções, como interseção com o eixo das abscissas e das ordenadas, o comportamento gráfico dessas funções quando $\mathrm{x}$ tende a 
valores cada vez maiores, menores ou tende a zero e assim fazer um estudo comparativo dos gráficos dessas funções.

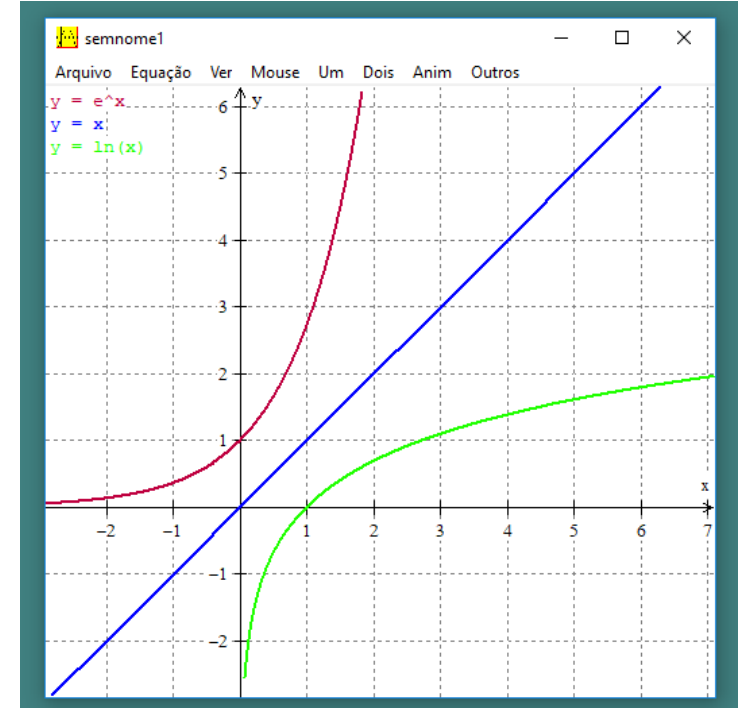

Figura 3: Funções Exponencial e Logarítmica

Como contribuição desse trabalho, as atividades propostas serão disponibilizadas para os professores de Matemática Básica e Cálculo, que poderão aplicá-las em sala de aula, com o uso de programas gráficos existentes nos celulares dos alunos ou levá-los a um laboratório de informática.

Por meio do questionário aplicado entre os alunos participantes, foi possível constatar que $67 \%$ deles nunca usou tecnologia ao estudar Matemática.

Todos os alunos pesquisados consideraram que as atividades aplicadas foram motivadoras, despertaram seu interesse e promoveram o aprendizado do estudo de funções.

Conforme mostra a Figura 4, a totalidade dos alunos participantes da pesquisa considerou que o estudo de funções com o uso do software Winplot foi muito bom e bom.

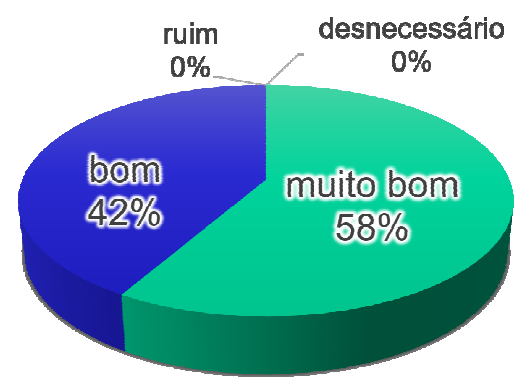

Figura 4: Opinião sobre o estudo de funções com o uso do Winplot 


\section{CONSIDERAÇÕES FINAIS}

Esse trabalho promoveu a reflexão a respeito do que deve ser abordado para minimizar as dificuldades que os alunos apresentam nas disciplinas de Cálculo.

Durante a aplicação das atividades foi possível observar que o uso da tecnologia motivou os alunos, proporcionou a construção de conhecimentos e a superação de dificuldades encontradas por eles ao estudar funções, tanto no aspecto algébrico e também gráfico.

Os comentários e sugestões dos alunos no questionário também evidenciaram que o uso da tecnologia auxiliou a minimizar dificuldades básicas de conteúdos matemáticos. alcançados.

Sendo assim, considera-se que os objetivos delineados nesse trabalho foram

É importante ressaltar que nessa pesquisa o software Winplot foi usado com o objetivo de dinamizar o estudo de funções e motivar os alunos, porém as atividades propostas podem ser desenvolvidas com programas gráficos obtidos nos celulares dos alunos, viabilizando o estudo e tornando-o acessível, mesmo sem o auxílio de computadores.

\section{REFERÊNCIAS}

CORRÊA, P.M.D. Logotipos, funções e Geogebra: Uma combinação bem-sucedida. In: Revista do Professor de Matemática ${ }^{\circ}$. 86, $1^{\circ}$. Quadrimestre de 2015. SBM.

GIRALDO, V. Funções em eixos paralelos. In: Revista do Professor de Matemática $\mathrm{n}^{\circ}$. 81, $2^{\circ}$. Quadrimestre de 2013. SBM.

JESUS, A.R. Painel II: WINPLOT (versão português). In: Revista do Professor de Matemática. SBM. n. ${ }^{\circ} 47.2001$.

MEYER, J.F.C.A.; SOUZA JÚNIOR, A.J. A utilização do computador no processo de ensinar-aprender Cálculo: a constituição de grupos de ensino com pesquisa no interior da universidade. Zetetiké. Revista semestral do Cempem. Universidade Estadual de Campinas. v.10, n. ${ }^{\circ}$ 17/18. São Paulo, 2002.

PONTE, J.P.; OLIVEIRA, H.; VARANDAS, J.M. O Contributo da Tecnologias de Informação e Comunicação para o Desenvolvimento do Conhecimento e da Identidade Profissional. J.P. da Ponte: Artigos e Trabalhos em Português. 2003. disponível em: http://www.educ.fc.ul.pt/docentes/jponte/artigos_pt.htm. Última consulta em 18/11/2009.

Persp. Online: exatas \& eng., Campos dos Goytacazes, 23 (08) 41 - 47 - 2018

seer.perspectivasonline.com.br 
SILVA, B.A.; MANRIQUE, A.L.; BIANCHINI, B.L.; DUBUS, M.T.G., SOUZA, V.H.G. Atividades para o estudo de funções em ambiente computacional. São Paulo: Iglu, 2002.

TAJRA, S.F. Informática na Educação: novas ferramentas pedagógicas para o professor na atualidade. 8. ${ }^{\mathrm{a}}$ edição. São Paulo: Érica, 2008.

VIANNA, C.C.S. Obstáculos referentes ao desenvolvimento do conceito de função. In: Didática do cálculo: epistemologia, ensino e aprendizagem. 1. a edição. São Paulo: Editora Livraria da Física, 2016. 